\section{Translation strategies used by Iranian translators in translation of idioms for movie subtitles: The case of Forrest Gump movie}

\author{
Behagh, Maliheh
}

English Department, Isfahan (Khorasgan) Branch, Islamic Azad University, Iran (Malihehbz@gmail.com)

Rezvani, Ehsan $\triangle$

English Department, Isfahan (Khorasgan) Branch, Islamic Azad University, Iran (rezvaniehsan_1982@yahoo.com)

Received: 1 May 2018

Available Online: 18 June 2018

Revised: 21 May 2018 DOI: $10.5861 /$ ijrsll.2018.3002

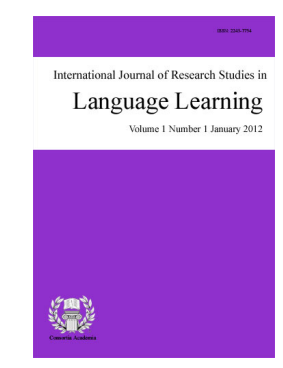

ISSN: 2243-7754 Online ISSN: 2243-7762

OPEN ACCESS

\begin{abstract}
The present research was an attempt to explore the translation strategies used in translation of idiomatic expressions from English to Persian. In this regard, a biographic film (Forrest Gump, 1994) was opted to provide us with some prevailing idioms. Initially, all idiomatic expressions were selected from the original language movie. The selected idioms were compared with three different translations from Baran Film Company (2014), Mehdi Najarian (2013) and zilkada_dvd@yahoo.com in order to find the types of translation strategies used by these translators. The comparison focused on the type of shift based on Viney and Darbelent (1958) theory. For this aim, a table in three columns was established, first column contained the idiomatic expressions, the second indicated relative corresponding translations and the last one determined the translation strategy types. The frequency of occurrence of every translation strategy was counted. Having analyzed the data, the results revealed that for translation of idiomatic expressions, the most commonly used strategy was correspondence. In this respect, calque and loan words showed very limited frequency.
\end{abstract}

Keywords: culture; idiom; subtitle; translation; translation theory 


\section{Translation strategies used by Iranian translators in translation of idioms for movie subtitles: The case of Forrest Gump movie}

\section{Introduction}

One of the most common applications of translation is in making movie subtitle. Subtitle is a form of indirect speech in which voice is coming from another channel. Accordingly, subtitle indicates character's speech but in written from. Subtitles mainly contain dialogue in source language form, another language form or both of them for different purposes. Subtitle in another language form is mostly used in translational cinema. Since the main application of subtitle is supplying translated version of a film in another language, exploiting a good translation is demanded.

A good translation gives to audience the same conception as what native audience gets from the original. Jakabson (1959) remarks that translation is not just decoding and encoding symbols into another language, but it is a process of information substitution. By paying attention to translation as information equivalence and on other hand by considering the different cultures between two languages, conducting a conceptual equivalence does not seem a simple task. The issue in translation process has employed theorists' mind and cause so many discussion in this respect. Part of problems which translators face them refer to cultural and linguistic issues. The issues are highlighted in translating idioms. Idiom is "a group of words whose meaning is different from the meaning of the individual words" (Hornby, 2005, p. 643). Therefore, translation of an idiom via translating its constituent elements is not understandable in target language.

In this regard an expert translator considers all concepts of a phrase in order to keep all aspects of that in target language in translation procedure. Baker (1992) states that translation of idiomatic expressions requires two points: the ability in interpreting an idiom as well as the ability in rendering various aspects of an idiom into the target language. The present research is considering translation of idiomatic expressions for the purpose of reaching applied strategies in the process of translation. Therefore, the researcher investigated the following question:

$>\quad$ What are the most commonly used translation strategies by Iranian translators in translating idioms for subtitles in the movie Forrest Gump?

\section{Review of Literature}

The following sections provide a brief review of the literature on the topic.

\subsection{Translation}

Considering translation of idioms in a movie subtitle is desired to consider translation at first. In 19th century because of scientific interactions and either due to economic or commercial needs, field of translation became prominent. Initially, knowing more than one language was sufficient to accomplish this task. But later by occurring some problems, individuals engaged in translation discovered it as a technical job; therefore, translation should be thought in order to present correct and beneficial target text.

\subsection{Definition of Translation}

However it is difficult to define the exact concept of translation, at whole translation is a process in which a translator conveys at least the meaning of source text into the target text. Having this outlook establish the wrong mentality that the task can be accomplished by individuals who know more than one language. For representing definition about translation pointing to theorists' viewpoints demands, Newmark (1988) remarks that translation 
Translation strategies used by Iranian translators in translation of idioms for movie subtitles

is a process of changing a written massage from one language into the other language in the way that the author intended the text. According to the definition the first important factor is conveying the intention.

In other expression, by dividing a language into the form and function, formal and dynamic equivalence are derived. Eugene Nida (1991) Nida (1969) claimed that remaining source language form in target language arises from formal equivalence, but in dynamic equivalence translators just convey the intention. Bell declared that "translation is the expression in another language of what has been expressed in another, preserving semantic and stylistic differences" (Bell, 1991, p. 5). In the definition the focus is on preserving semantic and stylistic differences. It is clear that semantic and stylistic differences mostly root in culture. While, Hatim and Mason (1990) presented different explanation of translation. They claimed that translation is "a communication process that takes place within a social context" (p. 3). According to another different definitions of translation, it is found out that many theorists in the field of translation have the same opinion about meaning equivalence which should be conveyed into the target text. Mona Baker (1992) confirms the tern meaning equivalence because she believes that the goal of translation is at first transferring the meaning; thus translators deal with unit of meaning.

\subsection{Viney and Darbelnet Theory}

Viney and Darbelnet (1958) present a general strategy in translation procedure which overrule all kinds of phrases; from primary and simple ones to complex and obscure notes. They classify translation methods into two main groups which all together cover seven concrete procedures. The two groups are direct translation and oblique translation.

Direct Translation Procedure - Direct translation is the most common style in which translator is usually in fatigues or rush. In this case translators fill a lexical gap by parallel words in target language that sometimes some mistakes occur with this style:

$>$ Preserving the same word order or phrasing of the source text.

$>\quad$ Using the same punctuation placement

$>\quad$ Not rewriting sentences that just don't work

$>\quad$ Losing the sense of the original text by using the exact same words, idioms, verb tenses and etc. of the source language

The variety of direct translation cause to sort out them in three types:

Loan words or borrowing - It is a procedure in which translators uses the foreign word or phrase in target text but in target language graph. The loan word is usually familiar to target readers and is known in their lexicon. In fact a loan word is a word adopted from one language into another language without translating. These words are different from cognates which are similar words in two or more languages with the same etymological origin. Sometime a loan word occurs with a very little change in target text. For example the Persian words " "تكنولوزى are the loans of "balcony and technology" from English. Due to the language penetration almost all languages have numerous loan words from English.

Calque or loan translation - Calque is a kind of borrowing in which translators express translation of original elements literally. This case keeps the syntactic structure of target text but introduce a new construction and mode of expression in language. In other words calque is one resulting from bilingual interference in which the internal structure from bilingual interference in which the internal structure of a borrowed word or phrase is maintained but its morphemes one replaced by those of the native language. For example the English expression of "keep the result under your hat" intends to keep the result a secret. Persian translators can convey it directly by "كلاهت نكگه دار زير" instead of" لو ". In this case the expression in target language seems new for target readers but the intention can be conveyed by the direct translation.

Literal translation - Literal translation or word-for-word translation is another type of direct translation which transfers a source text to a grammatical and meaningful text in target language. In the procedure the 
translator focuses on source text lexis but on target text grammar. In practice literal translation mostly accurse between two same family language which shave the same or near culture such as French and Italian. The best Persian example for this type of translation is translating religious texts like the Bible or Quran.

Oblique Translation Procedure - When a direct translation leads a text to a mistake, translators get it right by changing the word order, changing the punctuations according to the target text rules, rewriting sentences and some other technics which convert direct translation to oblique translation. Oblique translation is due to structural and metalinguistic differences between languages. In this case more complex methods are employed to create an exact and sufficient text in target language. As the procedures come sophisticated to mind, it can imply profound knowledge of translator in this task. Oblique translation is contained four types:

Transposition - It is a process that part of speech sequence is changed in target text. It is considered as a shift in word class. Grammatical structures are different in different languages. Thus, transposition is often used in most of translations. As the technic depends on operates at grammatical level which is replacement of a word class by another word class without changing the meaning. For the example between Persian and English, it suffices to say that almost in every fluent translation, transposition technic is used.

Modulation - This is a second technic belongs to oblique translation. Modulation in translation means using a phrase in target language that is different from source language but convey the same idea. It is a change semantically and is either a shift in point of view but carries a same conception. The important point in modulation is that it endows the same idiomatically on the target text in a way that the target reader is left with the illusion that she/he is reading the original text. A good example between English and Persian can be the phrase of "take it easy" by reforming to" سخت نكير ".

Correspondence or equivalence - This method expresses something in a completely different way. The creative technic is either called reformulation. Viney and Darbelnet suggest that, if this procedure is applied during the translation process, it can maintain the stylistic impact of the source text in the target text by using completely different wording. They claim that the phrases translated by this method are listed in bilingual dictionaries as "full equivalents". Translating an idiom or a proverb or every other fixed expression by another equal fixed expression in target language is a good example for this kind of technic.

Adaptation - When cultural differences between two languages cause to prevent us from understanding, this method is applied for transferring. Adaptation is not to be confused with localization. Newmark defines adaptation, taken from Vieny and Darbelent, as "The use of a recognized equivalent between two situations. It is a process of cultural equivalence" (Newmark, 1988, p. 53).Transferring the acquainted idiom "to carry coal to Newcastle" to its Persian equivalence "زيره به كرمان بردن" is a good example of this method.

\subsection{Classifications of Idioms}

Various classifications have been represented by many scholars. Newmark (1988) points out to many aspects for classification of idioms. He considers semantic and constructional point of view, fixedness and variability, function, stylistics and etymology. Therefore, different aspects of idioms cause different classification to occur.

\section{Method}

\subsection{Research Design}

The present study is a descriptive one which will provide the results in quantitative terms based on frequency counts. 


\subsection{The Corpus of the Study}

The American film by Robert Zemeckis in 1994 is adopted for the research. This is a biographic film based on Forrest Gump novel. The title character retells his entire life step by step. He experiences many adventures during his life; from childhood love and championship to shrimping and Vietnam War. As this movie is a biographic type and tells about routine life, it contains lots of casual phrases and fixed expressions which can be beneficial for the purpose of the study. Therefore, existing numerous idiomatic expressions inspired the researcher to choose the film as the case of the study. The aim of this research is obtaining common strategies for translation of idiomatic expressions from English to Persian. For this purpose different translated version of the film in the form of Persian subtitle were considered. They are products of Baran Film Company (2014), Mehdi Najarian (2013) and zilkada_dvd@yahoo.com.

\subsection{Instruments}

Forrest Gump movie with different Persian subtitles were essential instruments in the research. As the idioms should be selected from original language version of the film, the English language version was the first instrument which is obtained from You Tube. In the next step, three diverse Persian subtitles were used via which the equivalent idioms could be found. The subtitles were downloaded from isubtitle.ir. DVD player is a lateral instrument for the certain purpose that is plying the movie. For the ease of procedure in this research, the idioms were collected from original version of the film but their equivalence were extracted from printed subtitles files.

\subsection{The Procedures}

Through the study, initially all idiomatic expressions were selected from the original language movie. To make sure all idioms were included, the author reviewed the film for 2 times. After extracting idiomatic expressions, they were corresponded with their Persian equivalences from downloaded Persian subtitles. Then, a table in three columns was established in order to indicate relative translations and the types based on Viney and Darbelnet model; as the sample below. First column contained idiomatic expressions in source language. Second column indicated relative corresponding translations in Persian subtitles and finally, last column determined the translation type. The results were provided quantitatively upon frequency counts.

\subsection{Data Analysis}

The sample, including 46 idioms was collected from the movie which were corresponded to their translations. They were prepared and written in a table like the one above. The first column contained the fixed expression in native language. Second column was filled by various relative corresponding translations in the subtitles and the last column determined the type of translation based on Viney and Darbelnet (1958) Model. The frequency of occurrence of every translation strategy was counted.

\section{Results}

The table below shows the statistics of the study for idioms. The first column contains strategies of translation and the second one indicates relative frequency. From a total 46 idioms with 3 different translation which offer us 138 translated phrases, just one of them is loan, 2 applied calque, 23 are literal translation, 13 are transposition, 44 are modulation, 47 are correspondence, 2 are adaptation and 6 are omission. In third column frequency of each theory is stated as the form of percentage. It can be concluded that correspondence is the most prevailing used strategy for idiom translation with $34 / 05$ percent. The least frequently used one is loan translation which have a little usage in idiom translation procedure between English and Persian. Figure1 reveals the expanse of usage of all strategies for translation of idiomatic expression by a glance. 
Behagh, M., \& Rezvani, E.

Table 1

Frequency of Idioms Translation Strategies

\begin{tabular}{lccc}
\hline \multicolumn{1}{c}{ Theory } & Frequency & Percent & Cumulative percent \\
\hline Loan & 1 & 0.72 & 0.72 \\
Calque & 2 & 1.44 & 2.16 \\
Literal & 23 & 16.66 & 18.82 \\
Transposition & 13 & 9.42 & 28.24 \\
Modulation & 44 & 31.88 & 60.12 \\
Correspondence & 47 & 34.05 & 94.17 \\
Adaptation & 2 & 1.44 & 95.61 \\
Omission & 6 & 4.34 & 99.95 \\
\multicolumn{1}{c}{ TOTAL } & 138 & 99.95 & Almost 100 \\
\hline \multicolumn{1}{r}{}
\end{tabular}

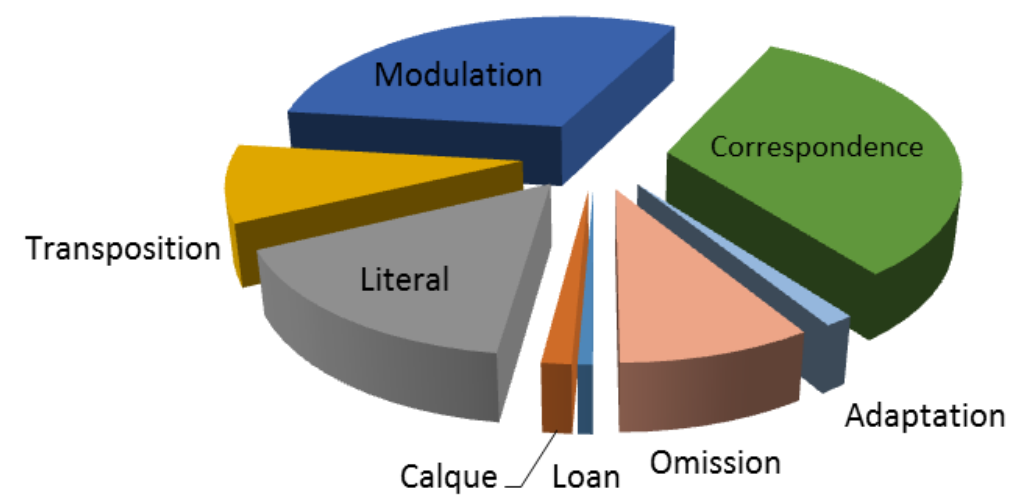

Figure 1. Pie diagram of idioms translation strategies

\section{Discussion}

As an outright answer to the research that was "what are the most commonly used translation strategies by Iranian translators in translating idioms for subtitles in the m movie Forrest Gump?" should be stated that correspondence is the most commonly used strategy in this respect by 34.05 percent of use frequency. After correspondence, modulation accesses more percentage among these strategies. It shows that when there is a suitable equivalence for translating idiomatic expressions, translator elects it as a prefer choice. If a translator does not strike with a beneficial equivalence, she/he modulates it by other different words to convey the conception.

According to Table 1 and the relative diagram, the least usage of strategies belong to loan with 0.72 percentage and calque with 1.44 percentage. It reveals that Persian audience have a very little familiarity of English lexicons and phrases. This can be a reason in offering a short explanations beside applied a loan word. In previous sections, it was explained that Viney and Darbelnet theory has two main branches; direct translation and oblique translation. By paying attention to the table 2 it is proved that 28.24 percentage of used strategies belongs to direct translation that are: loan, calque, literal and transposition. 67.37 percent of used theories are oblique translation that are Modulation, correspondence and adaptation. 4.34 percent of idiomatic expressions are omitted during translation procedure.

In some previous studies, the classification of translated idioms were based on other theories. In a research a classification was based on Mona Baker's theory which reveals that the translators use of all theories in their apropos occasions. In the present research the investigation was based on Viney and Darbelnet theory. The main reason for the choice is the comprehensiveness of this theory which allows the author to analyze all kinds of phrases. 


\section{Conclusion}

As a direct answer to the research questions, it should be mentioned that the most commonly used strategies for translation of idiomatic expressions are correspondence and modulation. Correspondence is the most prevailing strategy in this respect. This study has implication for translators, specially, for translators who are engaged in translation of movie subtitles because movies are usually full of idiomatic expressions and slang terms. Being familiar with translation theories and knowing prevailing strategies for translation of different kinds of fixed phrases and idiomatic expressions within texts facilitates translation procedure. The model used in the study is a comprehensive theory that translator can apply for all kinds of texts and phrases. The results of the study indicate that translators should hold correspondence theory at the top for translating idiomatic expressions. If the theories were not promoter in some cases, they should apply other suitable strategies. Moreover, this study has implications for translator trainers in heightening their awareness of the commonly used strategies that they can share with their translation trainees for translation of idioms.

\section{References}

Aguado-Giménez, P., \& Pérez-Paredes, P.-F. (2005). Translation-strategies use: A classroom-based examination of Baker's Taxonomy. Meta: Translators' Journal, 50(1), 294-311. https://doi.org/10.7202/010675ar

Backman, M. (2009). Introduction: The translation turn. University of Giessen.

Baker, M. (1992). In other words: A course book on translation. London: Routledge.

Bell, R. T. (1991). Translation and translating: Theory and practice. London: Routledge.

Berman, A. (1985). Translation and the trials of the foreign. UNESCO. Retrieved from http://www.unesco.uj.edu.pl/documents/2205554/33980917/BERMAN,\%20ANTOINE.pdf

Dries, J. (1995). Dubbing and subtitling: Guidelines for production and distribution. Düsseldorf, Germany: European Institute for the Media.

Forrest Gump SRT. (2014). isubtitle, from Baran Film Company. Retrieved from https://www.isubtitle.ir Hatim, B., \& Mason, I (1990). Discourse and the translator. Language in social life series. Longman. Hornby, A. S. (2005). Oxford advanced dictionary. New York: Oxford University Press.

Jacobson, R. (1959). On linguistic aspects of translation. Massachusetts: Cambridge.

Maltese, A., Scifo, L., Fratantonio, A., \& Pepi, A. (2012). Linguistic prosody and comprehension of idioms and proverbs in subjects of school age. Procedia - Social and Behavioral Sciences, 69, 2027-2035. https://doi.org/10.1016/j.sbspro.2012.12.161

Najarian, M. (2013). SRT Forrest Gump. Subtitlepedia. Retrieved from http://www.subtitlepedia.com Newmark, P. (1988). A textbook of translation. New York: Prentice hall.

Ni, L. (2009). For translation and theories. English Language Teaching, 2(2), 78-83.

Nida, E. A. (1969). Theories of translation. TTR: traduction, terminologie, rédaction, 4(1), 19-32. https://doi.org/10.7202/037079ar

Pym, A. (2014). Exploring translation theories. New York: Routledge.

Snell- Hornby, M. (1989). Translation studies: An integrated approach. Amsterdam: John Benjamins.

Steiner, R. (1967). The mystery of the human temperaments. German: Amazon.

Vinay, J. P. \& Darbelnet, J. (195). Comparative Stylistics of French and English. Amsterdam: John Benjamins.

Williams, L., Bannister, C., Arribas-Ayllon, M., Preece, A., \& Spasić, I. (2015). The role of idioms in sentiment analysis. Expert Systems with Applications, 42(21), 7375-7385.

https://doi.org/10.1016/j.eswa.2015.05.039

Zemeckis, R. (1994). Forrest Gump movie. Youtube. Retrieved from https://www.youtube.com 
Behagh, M., \& Rezvani, E. 